$\underset{\substack{\text { Clinical } \\ \text { nephron }}}{ }$

Practice
Nephron 2019;141:227-235

DOI: $10.1159 / 000495946$
Received: July 20, 2018

Accepted after revision: December 3, 2018

Published online: February 6, 2019

\title{
Utility of Cardiac Biomarkers in the Setting of Kidney Disease
}

\author{
Javad Savoj ${ }^{a}$ Brian Becerra ${ }^{b}$ Jin K. Kim ${ }^{b}$ Maria Fusaro ${ }^{c, d}$ Maurizio Gallieni ${ }^{\mathrm{e}}$ \\ Dawn Lombardo ${ }^{b}$ Wei Ling Lau ${ }^{f}$ \\ a Department of Internal Medicine, Riverside Community Hospital, University of California, Riverside School of \\ Medicine, Riverside, CA, USA; b Division of Cardiology, University of California, Irvine School of Medicine, Irvine, CA,

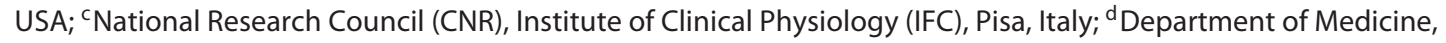

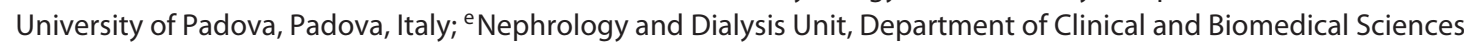 \\ "Luigi Sacco", University of Milan, Milan, Italy; ${ }^{f}$ Division of Nephrology, University of California, Irvine School of \\ Medicine, Irvine, CA, USA
}

\section{Keywords}

Biomarkers - Heart failure - Myocardial ischemia - Mortality . Chronic kidney disease

\begin{abstract}
Cardiovascular disease is prevalent in patients with chronic kidney disease (CKD) and responsible for approximately half of all CKD-related deaths. Unfortunately, the presence of CKD can lead to a challenging interpretation of cardiac biomarkers essential in accurate diagnosis and prompt management of heart failure and acute coronary syndrome. There is growing interest in novel cardiac biomarkers that may improve diagnostic accuracy reflecting myocardial injury, inflammation, and remodeling. Interpretation of these biomarkers in CKD can be complicated, since elevated levels may not reflect myocardial injury or wall tension but rather decreased urinary clearance with retention of solutes and/or overall CKD-associated chronic inflammation. In this review, we discuss the latest data on major and emerging cardiac biomarkers including B-type natriuretic peptide, troponin,
\end{abstract}

\section{KARGER}

๑) 2019 S. Karger AG, Basel

E-Mail karger@karger.com

www.karger.com/nef suppression of tumorigenicity 2, growth and differentiation factor-15, galectin-3, and matrix gla protein, and their diagnostic and prognostic utility in the CKD population.

(c) 2019 S. Karger AG, Basel

\section{Introduction}

The prevalence of cardiovascular disease in patients with chronic kidney disease (CKD) is as high as $73 \%$ and is responsible for approximately half of all CKD-related mortalities [1]. Atypical presentations of acute coronary syndrome (ACS) such as silent myocardial infarction (MI), nonspecific electrocardiogram changes due to comorbidities such as left ventricular hypertrophy or electrolyte abnormalities, and absence of accurate cardiac biomarkers not affected by kidney function have made ACS diagnosis in this patient population quite challenging [1]. A prospective study of emergency department (ED) visits found that CKD patients who presented with acute chest pain had non-ST elevation MI (NSTEMI) 
more than twice as often as patients with normal kidney function [2].

Heart failure is another challenging entity as it stems from a wide range of disorders and its severity and prognosis can be difficult to determine. Some of the symptoms such as dyspnea, orthopnea, and paroxysmal nocturnal dyspnea are due to congestion, while other symptoms such as weakness and exercise intolerance are due to decreased cardiac output. Fatigue due to uremia in CKD can confound heart failure symptomology and further delay definitive diagnosis and treatment.

Troponin has long been the gold standard for detecting myocardial ischemia in ACS, while B-type natriuretic peptide (BNP) and N-terminal proBNP (NT-proBNP) are established biomarkers in heart failure management. There is now growing interest in novel biomarkers that reflect myocardial injury, inflammation, and remodeling, which may improve diagnostic accuracy or predict clinical outcomes. Interpretation of biomarkers in CKD can be complicated, since elevated levels may not reflect myocardial injury but instead may be due to decreased urinary clearance and/or be a reflection of CKD-associated chronic inflammation. In this review, we discuss the diagnostic and/or prognostic utility of cardiac biomarkers including BNP, troponin, suppression of tumorigenicity 2 (ST2), growth and differentiation factor-15 (GDF-15), galectin-3, and matrix gla protein (MGP) in the CKD population (Table 1 ).

\section{Cardiac Troponin}

\section{Diagnostic Utility of Troponin}

Cardiac troponin $\mathrm{T}(\mathrm{cTnT})$ and I (cTnI) are sensitive markers of cardiac injury, particularly when used within the diagnostic cutoff of 99th percentile of healthy controls [3]. Interpretation of CTns in CKD patients remains controversial. Although the underlying cause of elevated cTn in non-ACS CKD patients is not well understood, it has been argued that reduced urinary clearance is unlikely to be the primary mechanism [4]. Rather, cTn reflects the evidence of ongoing myocyte damage [1], clinically silent "micro-MI" [5], or left ventricular hypertrophy [6]. Studies from rats with or without clamped kidney vessels showed that at high levels of cTnT similar to those observed after a large MI extrarenal clearance dominates, whereby there was no difference in cTnT clearance in rats with intact kidney function [7]. However, kidney clearance does play a role in the setting of stable low cTnT levels. Fridén et al. [7] examined 3 heart failure patients un- dergoing renal vein catheterization and determined the extraction index of cTnT to be $8-19 \%$.

An observational cohort study showed similar prevalence of increased cTnI and cTnT concentrations (33 and $43 \%$ respectively) in non-dialysis CKD patients [8]. Advantageous Predictors of ACS Evaluation was a prospective multicenter ED study in Europe that assessed the diagnostic performance of using highly sensitive (hs)-cTnT and hs-cTnI at zero and $1 \mathrm{~h}$ after presentation to the ED [2]. These markers were sensitive in ruling out NSTEMI in CKD patients with estimated glomerular filtration rate (eGFR) $<60 \mathrm{~mL} / \mathrm{min} / 1.73 \mathrm{~m}^{2}$, but the specificity to rule-in disease was lower than in patients with normal kidney function ( 88.7 vs. $96.5 \%$ for hs-cTnT, 84.4 vs. $91.7 \%$ for hs-cTnI). The investigators tested slightly higher concentrations as the cutoff, but this yielded little improvement at the cost of decreased sensitivity in higher risk CKD patients. They concluded that the higher prevalence of NSTEMI in the CKD population drives a higher positive predictive value and the same hc-cTn cutoff should be used until better diagnostic tools become available [2].

Gunsolus et al. [9] found similar results in a US study of 1555 adults presenting to the ED with ACS symptoms. Impaired kidney function did not significantly affect sensitivity or negative predictive value of hs-cTnI. Specificity decreased with lower eGFR stages, from $93-95 \%$ in persons with normal kidney function (eGFR $\geq 90 \mathrm{~mL} / \mathrm{min} / 1.73 \mathrm{~m}^{2}$ ) to $57-61 \%$ in eGFR $<30 \mathrm{~mL} / \mathrm{min} / 1.73 \mathrm{~m}^{2}$ ) to $40-41 \%$ in end-stage kidney disease (ESKD) patients on dialysis [9].

Evaluation via temporal cTN trends is recommended to guide accurate diagnosis of ACS. The National Academy of Clinical Biochemistry practice guidelines recommend a change in troponin level $>20 \%$ within $6-9 \mathrm{~h}$ (with $\geq 1$ value exceeding the 99th percentile) as diagnostic for acute MI among patients with advanced CKD $($ GFR $<15$ $\mathrm{mL} / \mathrm{min} / 1.73 \mathrm{~m}^{2}$ ) [10], but the validity of this approach in patients with stage 1-4 CKD is still unclear. In summary, elevated cTN has diagnostic utility in CKD patients but is limited by varying estimates of specificity [11].

\section{Prognostic Utility of Troponin}

In the study from Gunsolus et al. [9], there was a significant difference in 180-day mortality by hs-cTnI tertile (0-2.5 ng/L mortality 1.3\%; $2.5-10.6 \mathrm{ng} / \mathrm{L}$ mortality 6.0\%; and $>10.6 \mathrm{ng} / \mathrm{L}$ mortality $10.4 \%)$. In contrast, Lamb et al. [8] reported that $\mathrm{cTnT}$ concentration, but not $\mathrm{cTnI}$, was independently associated with all-cause death. A multiethnic cohort study that followed 3,218 patients for 12.5 years reported that hs-cTnT was a valid indicator of all-cause death and cardiovascular events in CKD patients [12]. 


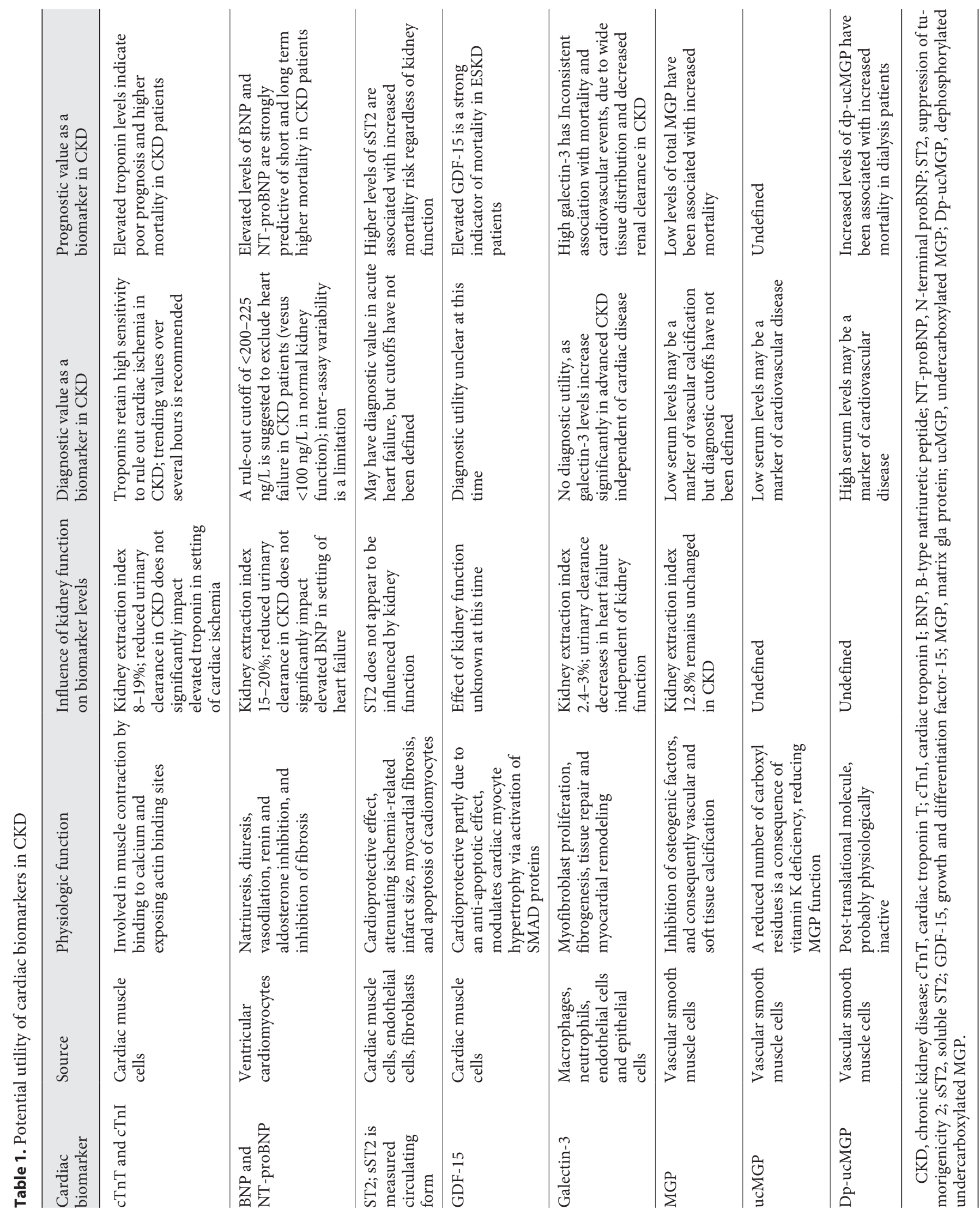




\section{BNP and NT-proBNP}

\section{Diagnostic Utility of BNP}

The natriuretic peptides are counter-regulatory hormones involved in volume homeostasis and cardiovascular remodeling. BNP is a 32 -amino-acid neurohormone that is released from cardiomyocytes in response to ventricular dilatation and pressure overload. BNP is derived from an intracellular 108-amino-acid precursor that is cleaved predominately into 2 fragments, yielding a 76-amino-acid N-terminal fragment (NT-proBNP) and BNP [13]. Stimulation of the natriuretic peptide receptor by BNP triggers natriuresis, diuresis, vasodilation, renin and aldosterone inhibition, and inhibition of fibrosis. The biological half-life of BNP ranges from 13 to $20 \mathrm{~min}$ and that of NT-proBNP from 25 to $70 \mathrm{~min}$. $\mathrm{BNP}$ is cleared via clearance receptors (NP receptor-C) and to a lesser extent by degradation by neutral endopeptidase (EC 3.4.24.11). NT-proBNP is cleared passively by organs with high blood flow (e.g., kidneys, liver and muscle). BNP and NT-proBNP are extracted renally by $15-$ $20 \%$ in healthy individuals and this renal clearance is maintained in the presence of moderate kidney dysfunction. However, for reasons that are unclear when eGFR falls below $30 \mathrm{~mL} / \mathrm{min} / 1.73 \mathrm{~m}^{2}$, NT-proBNP/BNP ratios increase [14].

Circulating BNP and NT-proBNP levels rise dramatically in the setting of heart failure. The Breathing Not Properly Multinational Study demonstrated that BNP values $>100 \mathrm{pg} / \mathrm{mL}$ diagnosed acute heart failure with high accuracy at $85 \%$ [15]. Subsequent studies suggested rule-out and rule-in diagnostic thresholds for acute heart failure in the setting of normal kidney function (BNP of $<100$ and $>500 \mathrm{ng} / \mathrm{L}$ respectively); when there is kidney dysfunction with eGFR $<60 \mathrm{~mL} / \mathrm{min} / 1.73 \mathrm{~m}^{2}$, a higher rule-out cutoff of $<200-225 \mathrm{ng} / \mathrm{L}$ is suggested [16]. Similar findings were seen for NT-proBNP in the ProBNP Investigation of Dyspnea in the Emergency Department (PRIDE) Study in which elevated NT-proBNP concentrations were stronger predictors of heart failure than clinical judgment [17]. A single NT-proBNP cutoff of $900 \mathrm{pg} / \mathrm{mL}$ provided similar diagnostic performance as BNP of $100 \mathrm{pg} / \mathrm{mL}$, but age-stratified cutoff points for NT-proBNP ( $\geq 450$ for ages $<50$ years, $\geq 900$ for $50-75$ years and $\geq 1,800 \mathrm{pg} / \mathrm{mL}$ for $>75$ years) performed the best [18]. If eGFR is $<60 \mathrm{~mL} / \mathrm{min} / 1.73 \mathrm{~m}^{2}$, a NT-proBNP value $>1,200 \mathrm{ng} / \mathrm{L}$ is best for exclusion of heart failure. However, exclusion of heart failure by NT-proBNP is less accurate in patients with eGFR $<30 \mathrm{~mL} / \mathrm{min} / 1.73 \mathrm{~m}^{2}$ [19]. Of note, consensus on diagnostic thresholds for
BNP and NT-proBNP remains uncertain due to lack of standardization between the several commercially available assays [14].

Non-cardiac conditions including CKD, advanced age, stroke, and critical illness can lead to BNP elevation independent of heart failure. While elevated BNP in CKD patients is partly due to reduced clearance, the prevailing evidence suggests that these levels are largely a true-positive finding and reflect underlying heart disease such as left ventricular hypertrophy or coronary atherosclerosis $[20,21]$.

\section{Prognostic Utility of BNP}

BNP and NT-proBNP are strong predictors of mortality. In the Acute Decompensated Heart Failure National Registry, the highest quartile admission BNP $\geq 1,730 \mathrm{pg} /$ $\mathrm{mL}$ was associated with 2.23 -fold increase in in-hospital mortality compared with BNP in the lowest quartile $(<$ $430 \mathrm{pg} / \mathrm{mL}$ ) [22]. Similarly, admission NT-proBNP >986 $\mathrm{pg} / \mathrm{mL}$ has been associated with an almost threefold increase in 1-year mortality (adjusted hazard ratio 2.88) [23]. As with cTn, serial BNP measurements are useful to assess prognosis. In the Valsartan Heart Failure Trial (Val-HeFT), a 4-month log-transformed continuous NTproBNP value added incremental prognostic value to a baseline measurement in a multivariable model for mortality prediction (hazard ratio 1.99) [24].

There is a strong relationship between elevated BNP/ NT-proBNP and cardiovascular mortality/events in ESKD [25]. In a multiethnic cohort study that followed 3,218 patients for 12.5 years, Gregg et al. [12] reported that BNP, NT-proBNP, and hs-cTnT were valid indicators of all-cause death and cardiovascular events in CKD patients, and associations were equivalent if not stronger as compared to non-CKD individuals. The prognostic value persisted even after the adjustment for eGFR and traditional cardiovascular risk factors [12]. However, studies have failed to identify consistent thresholds for BNP and NT-proBNP in CKD patients with decompensated heart failure that can help clinicians differentiate cardiac vs. non-cardiac causes of shortness of breath or volume overload. Overall, the optimal strategy for biomarker heart failure management using BNP/NT-proBNP remains unclear in CKD and ESKD patients.

Nesiritide, a recombinant BNP with vasodilatory properties, was previously explored as a therapeutic agent in heart failure. Nesiritide was approved in 2001 for use in acute heart failure patients, but early meta-analyses raised concerns about acute kidney injury and worse 
mortality outcomes. Subsequently, a randomized clinical trial of over 7,000 patients published in 2011 found increased rates of hypotension but no effect on mortality, rehospitalization, kidney function, or dyspnea [26]; lack of clinical benefit led to nesiritide being dropped from routine use.

\section{Suppression of Tumorigenicity 2}

\section{Diagnostic Utility of ST2}

ST2 is a novel cardiac biomarker that has emerged as an excellent prognostic indicator of mortality in ACS and heart failure in the general population $[27,28]$. The ST2 gene encodes 2 isoforms: soluble ST2 (sST2) and the membrane bound ST2 receptor (ST2L). These molecules are part of the interleukin-1 (IL-1) family and have important interactions with IL-33 that takes part in a complex network of signaling pathways in inflammation and cardiovascular disease. Both sST2 and IL-33 are upregulated in cardiomyocytes under the biomechanical strain $[28,29]$. The IL-33 molecule binds to ST2L activating mitogen-activated protein kinase-kinases and other intracellular signals, ultimately leading to the inhibition of nuclear factor- $\kappa B$, a master transcription factor regulating inflammation, apoptosis, and cell fate. Therefore, the IL-33/ST2L complex achieves a cardioprotective effect, attenuating fibrosis and apoptosis of cardiomyocytes [30]. The sST2 molecule, on the other hand, antagonizes the actions of the IL-33/ST2L interaction by acting as a decoy receptor [29], and is thereby proposed to be a negative prognostic indicator of cardiac disease [28]. It is the circulating sST2 molecule that is measured as a biomarker of cardiac disease. Other sources of sST2 during myocardial stress include cardiac endothelial cells and fibroblasts, and it is unclear how these sites contribute to overall sST2 levels in CKD [30].

Increased sST2 levels in CKD patients correlate inversely with eGFR and creatinine clearance $[28,31]$. It remains unclear whether elevated SST2 is a consequence of reduced urinary clearance or whether kidney injury itself triggers upregulation of sST2 expression. However, a recent study showed that sST2, unlike BNP, was not affected by the degree of kidney insufficiency in non-dialysis CKD patients with acute heart failure [32]. In a nonCKD cohort of 346 patients with acute heart failure, there was a significant positive correlation between ST2 and BNP [28]. Diagnostic cutoffs for ST2 have not yet been defined.

Utility of Cardiac Biomarkers in the Setting of Kidney Disease
Prognostic Utility of ST2

The data overall suggest an independent and incremental prognostic value of sST2 as a biomarker in the CKD population. In a non-CKD cohort of 346 patients with acute heart failure BNP did not predict mortality in the presence of a low ST2 level, suggesting that sST2 has superior biomarker specificity [28]. In a cohort of 883 participants with mean eGFRe of $49 \pm 19 \mathrm{~mL} / \mathrm{min} / 1.73$ $\mathrm{m}^{2}$, higher levels of sST2, GDF-15 and galectin-3 each were associated with greater mortality risk [33]. In patients hospitalized for heart failure, 2 separate studies showed that sST2 was associated with mortality independent of kidney function $[34,35]$. In a population of 423 hemodialysis patients, sST2 was found to have independent prognostic value over NT-proBNP in predicting all-cause death and cardiovascular events [36]. The molecular mechanisms behind sST2 as a cardiac biomarker in the context of acute or CKD needs further investigation.

\section{Growth and Differentiation Factor 15}

\section{Prognostic Utility of GDF-15}

GDF-15 is a novel biomarker with unclear diagnostic thresholds but has potential utility in prognosticating cardiac disease. Part of the transforming growth factor- $\beta$ superfamily protein, GDF-15 has been studied comparatively less than ST2. GDF-15 is not constitutively expressed in adult cardiac tissue but is upregulated when cardiomyocytes are under stress such as ischemic injury [37]. This enhanced GDF-15 production has been proposed to be a cellular defense program, as GDF-15 suppresses apoptosis and myocyte hypertrophy, the latter via activation of SMAD proteins $[37,38]$. Transgenic mice with cardiac-specific overexpression of GDF-15 were resistant to development of left ventricular hypertrophy under pressure-overload, and intravenous delivery of GDF-15 attenuated ventricular dilation and heart failure [38].

In patients with heart failure, circulating levels of GDF-15 are associated with mortality risk independently of established clinical and biochemical risk markers, including troponin T or BNP $[39,40]$. However, CKD and acute kidney injury are also independently associated with elevated levels of GDF-15 [39, 40]. In experimental animal models, GDF-15 levels are elevated when kidney injury is induced [41]. Precise mechanisms have not been elucidated, and it is unclear if upregulation of GDF-15 is induced by kidney injury, a decreased urinary clearance 
of GDF-15, or a combination of both, in humans. Nevertheless, GDF-15 was shown to be an independent marker of all-cause mortality in a population of patients with ESKD undergoing dialysis from the United States and Sweden, suggesting that GDF-15 may provide added prognostic value, regardless of the established kidney disease [42]. Further studies are needed to fully understand the pathophysiology behind GDF-15 upregulation under cardiac stress and how it relates to the prognostic power of GDF-15 and specificity as a biomarker in kidney disease.

\section{Galectin-3}

\section{Diagnostic Utility of Galectin-3}

Galectin-3 is a soluble $\beta$-galactoside-binding lectin expressed in macrophages, neutrophils, endothelial cells and epithelial cells. It is involved in myofibroblast proliferation, fibrogenesis, tissue repair, and myocardial remodeling [43]. Galectin-3 is also associated with kidney fibrosis and increased risk of incident CKD [44, 45] though our group did not find it to be a consistent biomarker for kidney fibrosis in the 5/6 nephrectomy rat model [46]. Current guidelines support the use of galectin-3 for additional risk stratification for myocardial injury (Level IA recommendation) and cardiac fibrosis (Level IIB recommendation) in heart failure patients [47]. However, as discussed in the next paragraph, galectin-3 is elevated in the setting of advanced CKD and is not a useful diagnostic biomarker of cardiac injury in this setting.

Interestingly, urinary clearance of galectin-3 is impaired in heart failure patients who have normal kidney function. In a study comparing healthy subjects with heart failure patients who had normal kidney function, urinary galectin- 3 was similar in the 2 groups ( 35.1 vs. $28.1 \mathrm{ng} / \mathrm{mL}, p=0.830$; corresponded to galectin-3 fractional excretion of 2.4 vs. $3 \%$ ) despite elevated plasma galectin-3 in heart failure patients (16.6 vs. $9.7 \mathrm{ng} / \mathrm{mL}$, $p<0.001$ ) [48]. Galectin-3 levels are significantly elevated in anuric hemodialysis patients without heart failure (median level $70.6 \mathrm{ng} / \mathrm{mL}$ ) [48]. In a small cohort study, Gopal et al. [49] reported that eGFR but not heart failure was a major determinant of galectin-3 levels. Similarly, in a cohort of ambulatory patients with heart failure in Spain, galectin-3 levels were significantly and inversely related to eGFR, independent of heart failure or left ventricular ejection fraction [50]. Median galectin-3 level significantly increased from 12.3 to 24.5 $\mathrm{ng} / \mathrm{mL}$ comparing patients with $\mathrm{eGFR} \geq 60$ versus patients with eGFR $<30 \mathrm{~mL} / \mathrm{min} / 1.73 \mathrm{~m}^{2}(p<0.001)$ [50].

\section{Prognostic Utility of Galectin-3}

In a cohort of ambulatory patients with heart failure in Spain, galectin-3 was not significantly associated with mortality after adjustment for eGFR [50]. In contrast, other studies have noted a significant association between elevated galectin-3 and adverse cardiovascular outcomes in CKD patients. The Ludwigshafen Risk and Cardiovascular Health (LURIC) and 4D studies analyzed $>3,500$ German patients and reported that galectin-3 concentrations were significantly associated with mortality in patients with eGFR $<60 \mathrm{~mL} / \mathrm{min} / 1.73 \mathrm{~m}^{2}$ after multivariate adjustment [51]. In a Japanese cohort of 423 chronic hemodialysis patients, galectin-3 had independent and incremental prognostic value over NT-proBNP for assessing risk of all-cause death and cardiovascular events during a mean follow-up period of $2.1 \pm 0.4$ years [36]. Median galectin-3 levels were $11.2 \mathrm{ng} / \mathrm{mL}$, lower than the levels reported in other dialysis cohorts mentioned above. Patients in the highest tertile $(\geq 15.2 \mathrm{ng} / \mathrm{mL})$ had a sevenfold increased risk of death or major cardiovascular events compared to patients in the lowest tertile $(<8.1 \mathrm{ng} /$ $\mathrm{mL}$ ) [36]. Finally, Tuegel and colleagues recently reported observational findings from 883 participants in 2 longitudinal pre-dialysis CKD cohorts: the Seattle Kidney Study and C-PROBE (Clinical Phenotyping and Resource Biobank Study). Mean eGFR was $49 \pm 19 \mathrm{~mL} / \mathrm{min} / 1.73$ $\mathrm{m}^{2}$ [33]. On multivariate adjustment, higher quartiles of serum galectin- 3 were associated with increased mortality risk. However, there was no association with heart failure, acute MI, or stroke [33].

Overall, the wide tissue distribution of galectin-3 expression and decreased renal clearance leading to systemic accumulation complicates the utility of galectin- 3 as a cardiac biomarker in CKD patients. However, galectin-3 may offer an incremental prognostic value for mortality as a biomarker in the dialysis population; this requires further study.

\section{Matrix Gla Protein}

\section{Diagnostic utility of MGP}

MGP is a $14 \mathrm{kDa}$ vitamin $\mathrm{K}$-dependent protein that is secreted mainly by vascular smooth muscle cells in the arterial medial layer and is a powerful inhibitor of vascular calcification [52]. MGP contains 5 gamma-carboxy- 
glutamic acid (Gla) residues, formed by post-translational modification of glutamic acid by gamma-glutamyl carboxylase, which requires active vitamin $\mathrm{K}$ (hydroquinone) as a coenzyme. There are 3 main vitamin $\mathrm{K}$ forms or vitamers: vitamin $\mathrm{K} 1$ or phylloquinone, vitamin $\mathrm{K} 2$ or menaquinones, and vitamin $\mathrm{K} 3$ or menadione, a synthetic molecule. These vitamers have different sources: vitamin $\mathrm{K} 1$ is found mostly in green leafy vegetables, while vitamin $\mathrm{K} 2$ can be found in fermented foods (e.g., Japanese natto) and are produced by intestinal bacterial flora. Vitamin K2 is the vitamer that is active in extra-hepatic tissues such as bone and arteries, regulating the formation of osteocalcin and MGP. MGP is a biomarker of cardiovascular health that correlates with the extent of cardiovascular calcification and with elevated risk of future cardiovascular morbidity and mortality [53].

MGP inhibits vascular calcification via 2 major mechanisms: direct inhibition of calcium crystal formation (it has a high affinity for calcium and hydroxyapatite) and indirect inhibition of osteoblastic phenotype change of vascular smooth muscle cells through the interaction with bone morphogenetic protein 2 [53]. There are several different circulating forms of MGP based on the level of carboxylation [53] (Table 1). Functionally active MGP is gamma-carboxylated and serine phosphorylated. Phosphorylation permits the cellular release of MGP, while carboxylation facilitates the binding of calcium ions.

Data on renal clearance of MGP are scarce. Decreased urinary clearance of MGP has been noted in CKD as well as in elderly non-CKD patients with other comorbidities [54]. In a cohort of patients with stable cardiovascular disease, both lower creatinine-eGFR and higher cystatin $\mathrm{C}$ were associated with lower undercarboxylated MGP (ucMGP) levels, even after adjustment for age, sex, race, body mass index, blood pressure, smoking, hypertension, diabetes, serum albumin, calcium, phosphorus, and fetuin-A levels [55]. However, a more stringent assessment of MGP clearance by Rennenberg et al. [56] found no relationship to kidney function. This study measured MGP levels in renal arterial and renal venous blood in humans with moderate to severe hypertension undergoing renal angiography. Patients had a wide eGFR range of 26-154 $\mathrm{mL} / \mathrm{min} / 1.73 \mathrm{~m}^{2}$, and calculated average renal fractional extraction of MGP was $12.8 \%$. This was not significantly related to the kidney function.

Vitamin K deficiency in CKD patients is common and this contributes to deficient levels of functional MGP [53]. ucMGP and dephosphorylated ucMGP (dp-ucMGP) have been proposed as biomarkers of vascular calcification and other cardiovascular diseases such as coro-

Utility of Cardiac Biomarkers in the Setting of Kidney Disease nary artery disease and aortic stenosis [57]. In ESKD patients, ucMGP levels are lower, while dp-ucMGP levels are higher than levels in the general population [57].

Another group of patients where ucMPG levels are reduced are those affected by calciphylaxis or calcific uremic arteriolopathy $[57,58]$, which is characterized by the calcification of cutaneous arterioles leading to skin lesions (e.g., livedo reticularis, skin ulceration and tissue necrosis) associated with severe pain. Calcific uremic arteriolopathy has been mainly described in ESKD patients but also occurs in non-CKD obese patients and in patients treated with corticosteroids or anticoagulant vitamin $\mathrm{K}$ antagonists. Long-term warfarin use is associated with reduced MGP activity and higher levels of cardiovascular calcification [58].

\section{Prognostic Utility of MGP}

Dp-ucMGP has been associated with increased mortality in ESKD patients and in patients with chronic stable ischemic vascular disease [57]. Observational studies have noted an association between warfarin therapy (which is associated with reduced MGP activity as noted above) with increased risk of MI and mortality [58, 59]. Of note, MGP may have a role as a therapeutic biomarker; Vitamin K2 treatment is being explored as a means to restore functional MGP levels and thus prevent cardiovascular damage [60].

\section{Summary}

There are robust data attesting to the diagnostic and prognostic value of troponins T and I in ACS and of natriuretic peptides in heart failure. Available data suggest that the prognostic power of these biomarkers holds true for CKD patients with heart disease, especially if levels are trended over time. Data on emerging biomarkers such as sST2, GDF-15, galectin-3 and MGP are limited. Each is distinct in its pathophysiological profile, with sST2 and galectin-3 being markers of myocardial fibrosis, GDF-15 representing an anti-apoptotic defense response, and MGP correlating with extent of vascular calcification. Studies to date have failed to identify diagnostic thresholds to improve the specificity of these cardiac biomarkers in the high-risk CKD population. There is conflicting evidence in regards to prognostic value of these biomarkers for cardiovascular mortality risk in CKD and their utility in guiding medical care. Overall, sST2 holds the most promise as a novel biomarker that offers incremental prognostic value when used with BNP to estimate 
mortality risk. More extensive pre-clinical and large-scale clinical investigations are needed to clarify the role of cardiac biomarkers including troponin, BNP, sST2, GDF-15, galectin-3, and MGP in the management of CKD patients with cardiovascular disease.

\section{Disclosure Statement}

The authors report no relationships that could be construed as a conflict of interest.

\section{References}

1 Freda BJ, Tang WH, Van Lente F, Peacock WF, Francis GS: Cardiac troponins in renal insufficiency: review and clinical implications. J Am Coll Cardiol 2002;40:2065-2071.

2 Twerenbold R, Badertscher P, Boeddinghaus J, Nestelberger T, Wildi K, Puelacher C, et al: 0/1-hour triage algorithm for myocardial infarction in patients with renal dysfunction. Circulation 2018;137:436-451.

3 Apple FS, Wu AH, Jaffe AS: European Society of Cardiology and American College of Cardiology guidelines for redefinition of myocardial infarction: how to use existing assays clinically and for clinical trials. Am Heart J 2002; 144:981-986.

4 Newby LK, Jesse RL, Babb JD, Christenson RH, De Fer TM, Diamond GA, et al: ACCF 2012 expert consensus document on practical clinical considerations in the interpretation of troponin elevations: a report of the American College of Cardiology Foundation task force on Clinical Expert Consensus Documents. J Am Coll Cardiol 2012;60:2427-2463.

5 Ooi DS, Isotalo PA, Veinot JP: Correlation of antemortem serum creatine kinase, creatine kinase- $\mathrm{MB}$, troponin I, and troponin $\mathrm{T}$ with cardiac pathology. Clin Chem 2000;46:338344.

6 Mishra RK, Li Y, DeFilippi C, Fischer MJ, Yang W, Keane M, et al: Association of cardiac troponin $\mathrm{T}$ with left ventricular structure and function in CKD. Am J Kidney Dis 2013; 61:701-709.

7 Fridén V, Starnberg K, Muslimovic A, Ricksten SE, Bjurman C, Forsgard N, et al: Clearance of cardiac troponin $\mathrm{T}$ with and without kidney function. Clin Biochem. 2017;50:468474.

8 Lamb EJ, Kenny C, Abbas NA, John RI, Webb MC, Price CP, et al: Cardiac troponin I concentration is commonly increased in nondialysis patients with CKD: experience with a sensitive assay. Am J Kidney Dis 2007;49: 507-516.

9 Gunsolus I, Sandoval Y, Smith SW, Sexter A, Schulz K, Herzog CA, et al: Renal dysfunction influences the diagnostic and prognostic performance of high-sensitivity cardiac troponin I. J Am Soc Nephrol. 2018;29:636-643.

$10 \mathrm{Wu}$ AH, Jaffe AS, Apple FS, Jesse RL, Francis GL, Morrow DA, et al: National Academy of Clinical Biochemistry laboratory medicine practice guidelines: use of cardiac troponin and B-type natriuretic peptide or $\mathrm{N}$-terminal proB-type natriuretic peptide for etiolo- gies other than acute coronary syndromes and heart failure. Clin Chem 2007;53:20862096.

11 Stacy SR, Suarez-Cuervo C, Berger Z, Wilson LM, Yeh HC, Bass EB, et al: Role of troponin in patients with chronic kidney disease and suspected acute coronary syndrome: a systematic review. Ann Intern Med 2014;161: 502-512.

12 Gregg LP, Adams-Huet B, Li X, Colbert G, Jain N, de Lemos JA, et al: Effect modification of chronic kidney disease on the association of circulating and imaging cardiac biomarkers with outcomes. J Am Heart Assoc 2017; 6:pii:e005235.

13 Levin ER, Gardner DG, Samson WK: Natriuretic peptides. N Engl J Med 1998;339:321328.

14 Thygesen K, Mair J, Mueller C, Huber K, Weber M, Plebani M, et al: Recommendations for the use of natriuretic peptides in acute cardiac care: a position statement from the Study Group on Biomarkers in Cardiology of the ESC Working Group on Acute Cardiac Care. Eur Heart J 2012;33:2001-2006.

15 Maisel AS, Krishnaswamy P, Nowak RM, McCord J, Hollander JE, Duc P, et al: Rapid measurement of B-type natriuretic peptide in the emergency diagnosis of heart failure. N Engl J Med 2002;347:161-167.

16 Dickstein K, Cohen-Solal A, Filippatos G, McMurray JJ, Ponikowski P, Poole-Wilson PA, et al: ESC Guidelines for the diagnosis and treatment of acute and chronic heart failure 2008: the Task Force for the Diagnosis and Treatment of Acute and Chronic Heart Failure 2008 of the European Society of Cardiology. Developed in collaboration with the Heart Failure Association of the ESC (HFA) and endorsed by the European Society of Intensive Care Medicine (ESICM). Eur Heart J 2008;29:2388-2442.

17 Januzzi JL, Camargo CA, Anwaruddin S, Baggish AL, Chen AA, Krauser DG, et al: The Nterminal Pro-BNP investigation of dyspnea in the emergency department (PRIDE) study. Am J Cardiol 2005;95:948-954.

18 Januzzi JL, van Kimmenade R, Lainchbury J, Bayes-Genis A, Ordonez-Llanos J, SantaloBel M, et al: NT-proBNP testing for diagnosis and short-term prognosis in acute destabilized heart failure: an international pooled analysis of 1256 patients: the International Collaborative of NT-proBNP Study. Eur Heart J 2006;27:330-337.
19 Chenevier-Gobeaux C, Claessens YE, Voyer S, Desmoulins D, Ekindjian OG: Influence of renal function on $\mathrm{N}$-terminal pro-brain natriuretic peptide (NT-proBNP) in patients admitted for dyspnoea in the Emergency Department: comparison with brain natriuretic peptide (BNP). Clin Chim Acta 2005;361: 167-175.

20 DeFilippi C, van Kimmenade RR, Pinto YM: Amino-terminal pro-B-type natriuretic peptide testing in renal disease. Am J Cardiol 2008;101:82-88.

21 Nishikimi T, Futoo Y, Tamano K, Takahashi M, Suzuki T, Minami J, et al: Plasma brain natriuretic peptide levels in chronic hemodialysis patients: influence of coronary artery disease. Am J Kidney Dis 2001;37:1201-1208.

22 Fonarow GC, Peacock WF, Phillips CO, Givertz MM, Lopatin M; DHERE Scientific Advisory Committee and Investigators: Admission B-type natriuretic peptide levels and inhospital mortality in acute decompensated heart failure. J Am Coll Cardiol 2007;49: 1943-1950.

23 Januzzi JL, Sakhuja R, O'donoghue M, Baggish AL, Anwaruddin S, Chae CU, et al: Utility of amino-terminal pro-brain natriuretic peptide testing for prediction of 1-year mortality in patients with dyspnea treated in the emergency department. Arch Intern Med 2006; 166:315-320.

24 Masson S, Latini R, Anand IS, Barlera S, Angelici L, Vago T, et al: Prognostic value of changes in $\mathrm{N}$-terminal pro-brain natriuretic peptide in Val-HeFT (Valsartan Heart Failure Trial). J Am Coll Cardiol 2008;52:997-1003.

25 Cheng YJ, Yao FJ, Liu LJ, Tang K, Lin XX, Li WJ, et al: B-type natriuretic peptide and prognosis of end-stage renal disease: a meta-analysis. PLoS One 2013;8:e79302.

26 O'Connor CM, Starling RC, Hernandez AF, Armstrong PW, Dickstein K, Hasselblad V, et al: Effect of nesiritide in patients with acute decompensated heart failure. $\mathrm{N}$ Engl J Med 2011;365:32-43.

27 Shimpo M, Morrow DA, Weinberg EO, Sabatine MS, Murphy SA, Antman EM, et al: Serum levels of the interleukin-1 receptor family member ST2 predict mortality and clinical outcome in acute myocardial infarction. Circulation 2004;109:2186-2190.

28 Rehman SU, Mueller T, Januzzi JL: Characteristics of the novel interleukin family biomarker ST2 in patients with acute heart failure. J Am Coll Cardiol 2008;52:1458-1465. 
29 Sanada S, Hakuno D, Higgins LJ, Schreiter ER, McKenzie AN, Lee RT: IL-33 and ST2 comprise a critical biomechanically induced and cardioprotective signaling system. J Clin Invest 2007;117:1538-1549.

30 Ciccone MM, Cortese F, Gesualdo M, Riccardi R, Di Nunzio D, Moncelli M, et al: A novel cardiac bio-marker: ST2:a review. Molecules 2013;18:15314-15328.

31 Bao YS, Na SP, Zhang P, Jia XB, Liu RC, Yu $\mathrm{CY}$, et al: Characterization of interleukin-33 and soluble ST2 in serum and their association with disease severity in patients with chronic kidney disease. J Clin Immunol 2012 32:587-594.

32 Kim MS, Jeong TD, Han SB, Min WK, Kim JJ: Role of soluble ST2 as a prognostic marker in patients with acute heart failure and renal insufficiency. J Korean Med Sci 2015;30:569575 .

33 Tuegel C, Katz R, Alam M, Bhat Z, Bellovich $\mathrm{K}$, de Boer I, et al: GDF-15, galectin 3, soluble ST2, and risk of mortality and cardiovascular events in CKD. Am J Kidney Dis 2018;72: 519-528.

34 Zhang R, Zhang Y, An T, Guo X, Yin S, Wang $\mathrm{Y}$, et al: Prognostic value of sST2 and galectin-3 for death relative to renal function in patients hospitalized for heart failure. Biomark Med 2015;9:433-441.

35 Bayes-Genis A, Zamora E, de Antonio M, Galán A, Vila J, Urrutia A, et al: Soluble ST2 serum concentration and renal function in heart failure. J Card Fail 2013;19:768-775.

36 Obokata M, Sunaga H, Ishida H, Ito K, Ogawa $\mathrm{T}$, Ando $\mathrm{Y}$, et al: Independent and incremental prognostic value of novel cardiac biomarkers in chronic hemodialysis patients. Am Heart J 2016;179:29-41.

37 Kempf T, Eden M, Strelau J, Naguib M, Willenbockel C, Tongers J, et al: The transforming growth factor-beta superfamily member growth-differentiation factor- 15 protects the heart from ischemia/reperfusion injury. Circ Res 2006;98:351-360.

$38 \mathrm{Xu}$ J, Kimball TR, Lorenz JN, Brown DA, Bauskin AR, Klevitsky R, et al: GDF15/MIC-1 functions as a protective and antihypertrophic factor released from the myocardium in association with SMAD protein activation. Circ Res 2006;98:342-350.

39 Anand IS, Kempf T, Rector TS, Tapken H, Allhoff T, Jantzen F, et al: Serial measurement of growth-differentiation factor-15 in heart failure: relation to disease severity and prog- nosis in the Valsartan Heart Failure Trial. Circulation 2010;122:1387-1395.

40 Kempf T, von Haehling S, Peter T, Allhoff T, Cicoira M, Doehner W, et al: Prognostic utility of growth differentiation factor-15 in patients with chronic heart failure. J Am Coll Cardiol 2007;50:1054-1060.

41 Zimmers TA, Jin X, Hsiao EC, McGrath SA, Esquela AF, Koniaris LG: Growth differentiation factor-15/macrophage inhibitory cytokine- 1 induction after kidney and lung injury. Shock 2005;23:543-548.

42 Breit SN, Carrero JJ, Tsai VW, Yagoutifam N, Luo W, Kuffner T, et al: Macrophage inhibitory cytokine-1 (MIC-1/GDF15) and mortality in end-stage renal disease. Nephrol Dial Transplant 2012;27:70-75.

43 de Boer RA, Daniels LB, Maisel AS, Januzzi $\mathrm{JL}$ : State of the art: newer biomarkers in heart failure. Eur J Heart Fail 2015;17:559-569.

44 Henderson NC, Mackinnon AC, Farnworth SL, Kipari T, Haslett C, Iredale JP, et al: Galectin-3 expression and secretion links macrophages to the promotion of renal fibrosis. Am J Pathol 2008;172:288-298.

45 O'Seaghdha CM, Hwang SJ, Ho JE, Vasan RS, Levy D, Fox CS: Elevated galectin-3 precedes the development of CKD. J Am Soc Nephrol 2013;24:1470-1477.

46 Lau WL, Khazaeli M, Savoj J, Manekia K, Bangash M, Thakurta RG, et al: Dietary tetrahydrocurcumin reduces renal fibrosis and cardiac hypertrophy in 5/6 nephrectomized rats. Pharmacol Res Perspect 2018;6:e0385.

47 Yancy CW, Jessup M, Bozkurt B, Butler J, Casey DE, Drazner MH, et al: 2013 ACCF/ AHA guideline for the management of heart failure: a report of the American College of Cardiology Foundation/American Heart Association Task Force on practice guidelines. Circulation 2013;128:e240-e327.

48 Meijers WC, van der Velde AR, Ruifrok WP, Schroten NF, Dokter MM, Damman K, et al: Renal handling of galectin-3 in the general population, chronic heart failure, and hemodialysis. J Am Heart Assoc 2014;3:e000962.

49 Gopal DM, Kommineni M, Ayalon N, Koelbl C, Ayalon R, Biolo A, et al: Relationship of plasma galectin-3 to renal function in patients with heart failure: effects of clinical status, pathophysiology of heart failure, and presence or absence of heart failure. J Am Heart Assoc 2012;1:e000760.

50 Zamora E, Lupón J, de Antonio M, Galán A, Domingo M, Urrutia A, et al: Renal function largely influences Galectin-3 prognostic value in heart failure. Int J Cardiol 2014;177:171177

51 Drechsler C, Delgado G, Wanner C, Blouin K, Pilz S, Tomaschitz A, et al: Galectin-3, renal function, and clinical outcomes: results from the LURIC and 4D studies. J Am Soc Nephrol 2015;26:2213-2221.

52 Barrett H, O'Keeffe M, Kavanagh E, Walsh M, O'Connor EM: Is matrix Gla protein associated with vascular calcification? A systematic review. Nutrients 2018;10:pii:E415.

53 Fusaro M, Crepaldi G, Maggi S, Galli F, D’Angelo A, Calò L, et al: Vitamin K, bone fractures, and vascular calcifications in chronic kidney disease: an important but poorly studied relationship. J Endocrinol Invest 2011;34:317-323.

54 Wei FF, Trenson S, Thijs L, Huang QF Zhang ZY, Yang WY, et al: Desphospho-uncarboxylated matrix Gla protein is a novel circulating biomarker predicting deterioration of renal function in the general population. Nephrol Dial Transplant 2017;33:11221128.

55 Parker BD, Ix JH, Cranenburg EC, Vermeer C, Whooley MA, Schurgers LJ: Association of kidney function and uncarboxylated matrix Gla protein: data from the Heart and Soul Study. Nephrol Dial Transplant 2009;24: 2095-2101.

56 Rennenberg RJ, Schurgers LJ, Vermeer C, Scholte JB, Houben AJ, de Leeuw PW, et al: Renal handling of matrix Gla-protein in humans with moderate to severe hypertension. Hypertens Res 2008;31:1745-1751.

57 Delanaye P, Liabeuf S, Bouquegneau A, Cavalier É, Massy ZA: [The matrix-gla protein awakening may lead to the demise of vascular calcification]. Nephrol Ther 2015;11:191200

58 Fusaro M, Tripepi G, Noale M, Plebani M, Zaninotto M, Piccoli A, et al: Prevalence of vertebral fractures, vascular calcifications, and mortality in warfarin treated hemodialysis patients. Curr Vasc Pharmacol 2015;13:248 258

59 Lin MC, Streja E, Soohoo M, Hanna M, Savoj J, Kalantar-Zadeh K, et al: Warfarin use and increased mortality in end-stage renal disease. Am J Nephrol 2017;46:249-256.

60 Fusaro M, Plebani M, Iervasi G, Gallieni M: Vitamin $\mathrm{K}$ deficiency in chronic kidney disease: evidence is building up. Am J Nephrol 2017;45:1-3. 